\title{
Handgrip Strength and Weight Predict Long-Term Mortality in Acute Kidney Injury Patients
}

\begin{abstract}
Keywords: Acute kidney injury; Long-outcome; Mortality; Predictors; Handgrip strength; Weight

\section{Abstract}

Introduction: Surviving acute kidney (AKI) patients have a higher late mortality. The negative impact of malnutrition on the early outcome of AKI patients has recently been confirmed by various studies. However, its impact after hospital discharge has not been studied. The objective of the study was to determine the role of anthropometric measurements and handgrip strength as predictors of mortality 180 days after discharge.

Methodology: Ninety-five consecutive AKI patients who were older than 18 y old and followed by AKI team were prospectively evaluated. Patient's characteristics were recorded, anthropometric measurements were taken, handgrip strength was measured, subjective global assessment and bio impedance were applied and blood samples were collected in two moments at hospitalization (at the beginning and end of nephrologist evaluation) and in three moments after hospital discharge (at 1 month, 3 and 6 months). Multivariable logistic regression was used to adjust confounding and selection bias.

Results: Age was $62.3 \pm 14.7$ years, prevalence of hospitalization in medical wards of $71.6 \%$, index of severity of AKI (ATN-ISS) was $28 \%$, early and late mortality rates were 13.6 and $25.6 \%$, respectively. Risk factors associated with late mortality were the number of comorbidities $(\mathrm{HR}=1.79,95 \% \mathrm{Cl}=1.45-2.46, \mathrm{p}=0.04)$, cancer $(\mathrm{HR}=1.89,95 \% \mathrm{Cl}=1.48$ 3.16, $\mathrm{p}=0.01)$, sepsis $(H R=1.47,95 \% \mathrm{Cl}=1.18-2.38, \mathrm{p}=0.03)$, no recovery of renal function at hospital discharge $(\mathrm{HR}=1.46,95 \% \mathrm{Cl}=1.02-2.16$, $\mathrm{p}=0.03)$, malnutrition at first evaluation ( $\mathrm{HR}=1.58,95 \% \mathrm{Cl}=1.14-2.94$, $p=001) p=0.01$ ), the hand grip value at the moment of last evaluation by nephrologist ( $\mathrm{HR}=1.81,95 \% \mathrm{Cl}=1.17-2.31, \mathrm{p}=0.04)$ and gain weigh $<1 \mathrm{~kg}$ between the moment at first evaluation by nephrologist and one month after hospital discharge ( $\mathrm{HR}=1.95,95 \% \mathrm{Cl}=1.29-3.3, \mathrm{p}=0.02)$.

Conclusion: Handgrip strength and gain weight were identified as predictors of late mortality. Simple and ease methods can be applied in AKI patients during and after hospitalization to diagnose nutritionally patients who are at higher risk for poor prognosis and, consequently intervention measures can be performed to improve survival in long term.
\end{abstract}

\section{Background}

Traditionally, most studies on AKI have focused on short-term outcomes often assessed at hospital discharge. However, recent studies have claimed that long-term outcome of patients after an AKI episode is also poor, ranged from $15 \%$ to $74 \%$ [1-5].

Nutritional status is condition that significantly contributes to an increased in-hospital mortality rate of these patients [6-9]. Fiaccadori et al. assessed 309 AKI patients and identified association between severe malnutrition and unfavourable prognosis [6]. A retrospective study by Obialo et al. showed association of values below $3.5 \mathrm{mg} / \mathrm{dL}$ of albumin and mortality in AKI patients [7]. Berbel et al. showed that low caloric intake, higher CRP levels, presence of oedema, lower resistance by bioelectrical impedance and lower nitrogen balance were significantly associated with higher risk of in-hospital death in AKI patients [8].

\section{Journal of}

Urology \& Nephrology

Patricia Santi Xavier, Cassiana Regina Goes, Marina Berbel Buffarah, Ana Claudia Soncini, André Luis Balbi and Daniela Ponce*

Botucatu School of Medicine, UNESP, Sao Paulo, Brazil

\section{Address for Correspondence}

Daniela Ponce, Distrito de Rubiao Junior, Botucatu School of Medicine, UNESP, Botucatu, Sao Paulo, Brazil, Tel: 5514 97625806; E-mail: dponce@fmb.unesp.br

\section{Submission: 03 May, 2016}

Accepted: 20 May, 2016

Published: 25 May, 2016

Copyright: (๑ 2016 Xavier PS, et al. This is an open access article distributed under the Creative Commons Attribution License, which permits unrestricted use, distribution, and reproduction in any medium, provided the original work is properly cited.

Although it is known that nutritional status can have impact on clinical outcomes, few studies have previously addressed the association of the nutritional markers and long-term outcome.

Vecchiarino et al. evaluated 213 hospitalized patients with pneumonia at admission and 30 days after hospital discharge and showed that malnutrition, inability to walk 50 meters without help and handgrip strength lower than $10 \mathrm{~kg}$ were associated with longer hospital stay, hospital readmission and death [10].

Kvale et al. cols assessed 346 critically ill patients seven months after intensive care unit (ICU) discharge and showed that $28 \%$ of patients reported to have lost $5-10 \mathrm{~kg}, 19 \%$ of $10-15 \mathrm{~kg}$ and $21 \% \mathrm{had}$ a maximum weight loss of more than $15 \mathrm{~kg}$ during hospitalization [11]. The body weight at the follow-up consultation compared with that before the ICU stay was higher in 15\% of patients, unchanged in $35 \%$ and lower in $50 \%$ of patients, which shows a persistent worsening of the nutritional status even after several months of hospital discharge and it may contribute to the poor prognosis of patients.

Considering the lack of information about association of the nutritional markers with long-term mortality after AKI episode, the objective of this study was to analyze the role of anthropometric measurements and handgrip strength as predictors of mortality in AKI patients 180 days after hospital discharge.

\section{Patients and Methods}

All procedures were approved by the ethics committee of our institution (Botucatu Medical School protocol number 2012/10638), and all participants gave their written consent.

\section{Study design}

From October 2012 to May 2014, 95 consecutive patients older than $18 \mathrm{y}$ with clinical diagnosis of AKI and suggestive clinical presentation of acute tubular necrosis (ATN) and followed up by the nephrology and nutrition team from the Botucatu School of Medicine were prospectively evaluated. 
Citation: Xavier PS, Goes CR, Buffarah MB, Soncini AC, Balbi AL, et al. Handgrip Strength and Weight Predict Long-Term Mortality in Acute Kidney Injury Patients. J Urol Nephrol. 2016;3(1): 8.

ISSN: $2380-0585$

Table 1: Nutritional parameters at initial and final moments of nephrologist evaluation in-hospital.

\begin{tabular}{|c|c|c|c|}
\hline Characteristics & Patients N=95 & Pacientes $\mathrm{N}=82$ & $\mathbf{p}$ \\
\hline & First nephologist evaluation & Last nephologist evaluation & \\
\hline Weight (kg) & $73.98 \pm 19.76$ & $71.10 \pm 19.43$ & 0.09 \\
\hline BMI $\left(\mathbf{k g} / \mathbf{m}^{2}\right)$ & $26.4 \pm 6.7$ & $24.8 \pm 5.7$ & 0.67 \\
\hline \multicolumn{4}{|l|}{ Nutritionalstatus $\mathbf{N}(\%)$} \\
\hline Severe malnourished & $1(1.05)$ & $1(1.22)$ & 0.51 \\
\hline Moderate malnourished & $7(7.37)$ & $7(8.54)$ & 0.58 \\
\hline Mild malnourished & $8(8.42)$ & $7(8.54)$ & 0.59 \\
\hline Well nourished & $22(23.16)$ & $22(26.83)$ & 0.21 \\
\hline overweigh & $21(22.11)$ & $14(17.07)$ & 0.19 \\
\hline Obesity & $36(37.89)$ & $31(37.80)$ & 0.69 \\
\hline \multicolumn{4}{|l|}{ SGAN(\%) } \\
\hline Well nourished & $30(31.58)$ & $28(34.14)$ & 0.43 \\
\hline Moderate malnourished & $47(49.47)$ & $42(51.22)$ & 0.49 \\
\hline Severe malnourished & 18(18.95) & $12(14.63)$ & 0.11 \\
\hline Handgrip (kg) & $13 \pm 10.48$ & $16.1 \pm 11.4$ & 0.04 \\
\hline $\mathbf{P A}\left({ }^{\circ}\right)$ & $4.96 \pm 1.37$ & $4.98 \pm 1.25$ & 0.73 \\
\hline Reatance (ohms) & $39.23 \pm 15.84$ & $43.07 \pm 15.02$ & 0.10 \\
\hline
\end{tabular}

BMI: Body Mass Index; SGA: Subjective Global Assessment ; PA: Phase Angle

The diagnosis of AKI was defined according to serum creatinine levels, as proposed by the KDOQI - Acute Kidney Injury [12]. The exclusion criteria were patients with AKI of other aetiologies, those needing chronic renal replacement therapy (dialysis or transplantation) or with history of severe chronic kidney disease (baseline serum creatinine $>4 \mathrm{mg}$ per $100 \mathrm{ml}$ ) and pregnant.

For sample size estimation, the Fisher-Belle formula was used, with the following variables: $30 \%$ long-term mortality prevalence in AKI patients, $95 \%$ confidence interval (CI), and 10\% sample error [13]. The result was 81 patients.

On admission, patient characteristics including age, gender, and concomitant diseases were recorded. Nutritional Assessment Protocol was composed by SGA (Subjective Global Assessment), biochemical parameters (C-reactive protein, albumin, hemoglobin, cholesterol, total lymphocyte count, phosphorus and potassium), anthropometry, bioelectrical impedance analysis (BIA) and handgrip strength. Biochemical examinations were performed; BIA and functional and anthropometric data were collected in two moments at hospitalization (atthe first and the last nephrology evaluation) and in three moments after hospital discharge (at 1 month, 3 and 6 months). All surviving patients during hospitalization were evaluated 30, 90 and 180 days after hospital discharge.

\section{Anthropometric measurements, BIA and handgrip strength}

Mobile patients were weighed on a digital scale and weight of immobilised patients was obtained using abed scale. Arm circumference and triceps skin-fold thickness (TST) were also evaluated. All measurements were performed three times by the same examiner, and the average value was adopted as the final result.
BIA was performed using the single frequency equipment Biodynamics model 450. It provided results including resistance (ohms), reactance (ohms) and phase angle $\left({ }^{\circ}\right)$. In patients treated by haemodialysis, it was performed 30 minutes after the end of the session.

Handgrip strengths were measured using a standard adjustable handle (TEC-60; Technical Products; Clifton, NJ, USA). All measurements were performed for the non-dominant hand, with the elbow supported on the bed, and a trained examiner administered all tests. The subjects performed three maximum attempts for each measurement, and the best performance of these tests was recorded. During testing, the participant was strongly encouraged to exhibit the best possible force. One-minute rests were given between each attempt to minimize fatigue effects $[14,15]$.

\section{Laboratory data analysis}

Total serum levels of C-reactive protein, albumin, glucose, creatinine, and serum urea nitrogen were measured using the dry chemistry method (Ortho-Clinical Diagnostics VITROS 950, Johnson \& Johnson, New Jersey, USA). Hemograms were obtained with a Coulter STKS hematologic autoanalyzer (Luton/ Bedfordshire, $\mathrm{UK})$.

\section{Statistical analysis}

The data are expressed as mean _ standard deviation or median (lower to upper quartile). Statistical comparisons between the groups for continuous variables were performed using Student's $t$ test for parameters with normal distributions. Otherwise, comparisons between groups were conducted using the Mann-Whitney. The chisquare test was used for all categorical data. Logistic regression was 
Citation: Xavier PS, Goes CR, Buffarah MB, Soncini AC, Balbi AL, et al. Handgrip Strength and Weight Predict Long-Term Mortality in Acute Kidney Injury Patients. J Urol Nephrol. 2016;3(1): 8.

ISSN: $2380-0585$

Table 2: Long-term nutritional parameters of AKI patients.

\begin{tabular}{|c|c|c|c|c|c|c|}
\hline Nutritional characteristics & $\begin{array}{c}\text { First nephologist } \\
\text { evaluation in-hospital }\end{array}$ & $\begin{array}{l}\text { Last nephologist } \\
\text { evaluation in-hospital }\end{array}$ & $\begin{array}{l}\text { After } 1 \\
\text { Month }\end{array}$ & $\begin{array}{l}\text { After } 3 \\
\text { Months }\end{array}$ & $\begin{array}{l}\text { After } 6 \\
\text { Months }\end{array}$ & $\mathbf{p}$ \\
\hline & $\mathrm{N}=95$ & $N=82$ & $N=71$ & $N=61$ & $N=61$ & \\
\hline Weight (kg) $N(\%)$ & $73.93 \pm 19.76$ & $71.10 \pm 19.43$ & $71.66 \pm 21$ & $77.34 \pm 21.21$ & $78.89 \pm 22.32^{a}$ & $<0.05$ \\
\hline BMI $\left(\mathbf{k g} / \mathbf{m}^{2}\right)$ & $26.41 \pm 6.99$ & $25.18 \pm 6.52$ & $25.58 \pm 6.30$ & $26.98 \pm 6.30$ & $27.58 \pm 7.27^{a}$ & $<0.05$ \\
\hline \multicolumn{7}{|l|}{ Nutritional status $\mathbf{N}(\%)$} \\
\hline Severely malnourished & $1(1.22)$ & $2(2.44)$ & $2(2.81)$ & $1(1.64)$ & $1(1.64)$ & 0.31 \\
\hline Moderately malnourished & $6(7.32)$ & $12(14.63)$ & $8(11.26)$ & 2(3.27) & $1(1.64)^{b}$ & $<0.05$ \\
\hline Mildly malnourished & $6(7.32)$ & $7(8.53)$ & $3(4.22)$ & $5(8.20)$ & $3(4.91)$ & 0.38 \\
\hline Well nourished & $21(25.61)$ & $18(21.95)$ & 19(23.17) & $15(24.59)$ & $16(26.22)$ & 0.08 \\
\hline overweigh & $18(21.95)$ & $14(17.07)$ & $15(21.12)$ & $13(21.31)$ & 11(17.02) & 0.34 \\
\hline SGAN(\%) & $82(100)$ & $82(100)$ & $71(100)$ & $61(00)$ & $61(100)$ & \\
\hline Well nourished & $33(40.24)$ & $27(32.92)$ & $34(47.89)$ & $43(70.49)$ & $46(75.40)^{\mathrm{a}}$ & $<0.05$ \\
\hline Moderate malnourished & $39(47.56)$ & $40(51.22)$ & $32(45.00)$ & $16(26.22)$ & $13(20.96)^{a}$ & $<0.05$ \\
\hline Severe malnourished & $10(12.19)$ & $15(18.29)$ & $5(7.04)$ & $2(3.28)^{a}$ & $2(3.28)^{a}$ & $<0.05$ \\
\hline Handgrip (kg) & $13.68 \pm 10.57$ & $16.47 \pm 11.33$ & $21.55 \pm 12.48$ & $24.72 \pm 13.19$ & $27.34 \pm 14.92^{\mathrm{a}}$ & $<0.05$ \\
\hline $\operatorname{PAF}\left(^{\circ}\right)$ & $5.06 \pm 1.35$ & $4.98 \pm 1.19$ & $5.29 \pm 1.05$ & $5.55 \pm 0.96$ & $6.18 \pm 1.03^{a}$ & $<0.05$ \\
\hline Reatance (ohms) & $41.88 \pm 14.55$ & $44.22 \pm 14.60$ & $45.02 \pm 15.63$ & $48.35 \pm 11.05$ & $52.21 \pm 10.76^{b}$ & $<0.05$ \\
\hline Extra cell water(\%) & $66.90 \pm 6.82$ & $60.40 \pm 6.56$ & $49.27 \pm 7.01$ & $48.19 \pm 6.59$ & $46.51 \pm 6.86^{a}$ & $<0.05$ \\
\hline
\end{tabular}

a: Significantly different from the first and the last evaluation of nephrologist in-hospital

b: Significantly different from the last evaluation of nephrologist in-hospital

c: Significantly different from the first and last evaluation of nephrologist in-hospitaland 1 month after hospital discharge

BMI: Body Mass Index; SGA: Subjective Global Assessment; PA: Phase Angle

used to predict late mortality. Handgrip strength and anthropometric measurements were tested as independent variables and adjusted by age, gender, comorbidities and creatinine and severity of AKI. Data analysis was performed using Sigma Stat 3.5 for Windows (Systat Software, Inc., San Jose, CA, USA). P values lower than 0.05 were considered statistically significant.

\section{Results}

Ninety-five consecutive AKI patients were evaluated. Among these patients, mean age was $62.3 \pm 14.7 \mathrm{y}, 62.6 \%$ were men, septic and ischemic were the main AKI etiology (32.6 and 29.2\%, respectively), the most of patients had co morbidities (70.4\%), AKIAKIN 3 was frequent in 63 patients, ATN-ISS was $0.28 \pm 0.10$ and 14 patients (13.7\%) died during the hospital stay. Eighty-two patients had hospital discharge and 4 patients lost the follow up (4.9\%). Recovery renal function was complete at hospital discharge in $23.2 \%$ of patients. The long-term mortality was $25.6 \%$. The demographic, clinical, and laboratory data are presented in Table 1.

Patients' weight at the first nephrologist evaluation was $73.7 \mathrm{~kg}$ \pm 19.3. During hospitalization, the most of patients had weight loss (83.3\%). The severe weight loss, defined as higher than $10 \%$, occurred in $33.7 \%$ of patients.

During hospital stay, the handgrip strength was the only nutritional parameters that presented significant difference. At the initial moment it was $13 \pm 10.5 \mathrm{~kg}$, while at the final moment it was
$16.1 \pm 11.4 \mathrm{~kg}(\mathrm{p}=0.04)$. There was no difference in body mass index (BMI), nutritional status, phase angle and reactance. Forty percent of patients were obese, while $16 \%$ were malnourished. Phase angle and reactance were $4.96 \pm 1.37$ and $39.23 \pm 15.84$ at first evaluation and $4.98 \pm 1.25$ and $43.07 \pm 15.02$ at the last in-hospital evaluation, respectively.

Table 2 shows the nutritional follow up of surviving AKI patients after hospital discharge. There was increase in weight $(73.9 \pm 19.8$ vs. $78.9 \pm 22.3, \mathrm{p}<0.05)$, in BMI $(26.4 \pm 6.9$ vs. $27.6 \pm 7.3, \mathrm{p}<0.05)$, in well nutrished according to SGA $(40.2 \% \times 75.4, \mathrm{p}<0.05)$, in handgrip strengths $(13.7 \pm 10.6 \times 27.3 \pm 14.9, \mathrm{p}<0.05)$, in phase angle $(5.1 \pm$ $1.4 \times 6.2 \pm 1.0, \mathrm{p}<0.05)$ and in reactance $(41.9 \pm 14.6 \times 52.2 \pm 10.8$, $\mathrm{p}<0.05)$.

Table 3-5 describes the clinical, nutritional and laboratory data of long-term survivors and non-survivors. There was no difference in gender $(\mathrm{p}=0.49)$, hypertension $(\mathrm{p}=0.47)$, diabetes $(\mathrm{p}=0.47)$, liver failure ( $\mathrm{p}=0.98)$, etiology of AKI $(\mathrm{p}=0.27)$, need for dialysis $(\mathrm{p}=0.26)$ and chronic kidney disease $(\mathrm{p}=0.82)$. The non-surviving group had higher number of comorbidities $(\mathrm{p}=0.031)$, cancer and sepsis ( $\mathrm{p}=$ 0.01 and 0.02 , respectively) and non-recovery of kidney function at hospital discharge moment $(\mathrm{p}=0.005)$, as shown in Table 3 .

Nutritional data are presented in Table 4 . There was no difference in anthropometric measures and in reactance and phase angle. Longterm non-survivors had lower weight and recovery of weight (75.34 \pm 21.21 vs. $71.45 \pm 22.03, \mathrm{p}=0.048$ and $3.3 \pm 1.4$ vs. $-0.3 \pm 0.1, \mathrm{p}=0.03$, 
Citation: Xavier PS, Goes CR, Buffarah MB, Soncini AC, Balbi AL, et al. Handgrip Strength and Weight Predict Long-Term Mortality in Acute Kidney Injury Patients. J Urol Nephrol. 2016;3(1): 8.

ISSN: $2380-0585$

Table 3: Clinical characteristics of acute kidney injury patients according to long-term survival.

\begin{tabular}{|c|c|c|c|}
\hline Characteristics & Survivors $\mathrm{N}=61$ & Non-survivors $\mathrm{N}=\mathbf{2 1}$ & $\mathbf{P}$ \\
\hline Male sex & $40(65,57)$ & $12(57,14)$ & 0.49 \\
\hline Age (years) & $61.20 \pm 13,83$ & $64,43 \pm 18.07$ & 0.19 \\
\hline Comorbidities $\mathbf{N}(\%)$ : & & & 0.031 \\
\hline no & $10(16.4)$ & $4(19)$ & \\
\hline 1 & $33(54.1)$ & $8(37.2)$ & \\
\hline 2 & 18(29.5) & $9(42.8)$ & \\
\hline \multicolumn{4}{|l|}{ Type of Comorbidities N(\%): } \\
\hline Hypertensio & $39(63.93)$ & $11(55.00)$ & 0.47 \\
\hline Diabetes & $30(49.18)$ & $8(40.00)$ & 0.46 \\
\hline Liverfailure & $3(4.92)$ & $1(4.76)$ & 0.98 \\
\hline cancer & $2(3.28)$ & $4(19.05)$ & 0.01 \\
\hline Time of hospitalization $\mathrm{N}(\%)$ : & $25.77 \pm 18.05$ & $28.90 \pm 17.45$ & 0.29 \\
\hline Admission $\mathbf{N}(\%)$ : & & & 0.01 \\
\hline UCI & 12(19.6) & 16(76.19) & \\
\hline Clinicalward & $43(70.5)$ & $3(14.3)$ & \\
\hline Surgicalward & $6(9.8)$ & $2(9.5)$ & \\
\hline CKD N(\%): & $19(31.15)$ & $9(42.86)$ & 0.33 \\
\hline AKIN N(\%): & & & 0.26 \\
\hline I & $13(21.31)$ & $2(9.52)$ & \\
\hline II & $15(24.59)$ & $4(19.05)$ & \\
\hline III & $33(54.10)$ & $15(71.43)$ & \\
\hline Etiologyof AKIN (\%) & & & 0.27 \\
\hline Ischemic & $18(29.50)$ & $5(23.80)$ & \\
\hline Septic & $22(36.06)$ & $6(28.60)$ & \\
\hline Nephotoxic & $11(18.03)$ & $4(19.04)$ & \\
\hline Mix & $6(9.83)$ & $4(19.04)$ & \\
\hline Pos renal & $1(1.63)$ & 0 & \\
\hline Others & $3(4.92)$ & $2(9.52)$ & \\
\hline Presence of sepsis $\mathrm{N}(\%)$ : & $20(32.79)$ & $11(57.89)$ & 0.02 \\
\hline Dialysis N(\%): & $13(21.31)$ & $5(23.81)$ & 0.82 \\
\hline ATN-ISS N(\%): & $0.21 \pm 0.19$ & $0.25 \pm 0.19$ & 0.41 \\
\hline Recovery of kidney function & & & 0.005 \\
\hline no & $8(13.1)$ & $16(76.2)$ & \\
\hline Partial & $12(19.7)$ & $3(14.3)$ & \\
\hline Total & $41(67.3)$ & $2(9.5)$ & \\
\hline
\end{tabular}

UCI: Unit Intensive Care; AKI: Acute Kidney Injury; ATN-ISS: Acute Tubular Necrosis-Individual Specific Score

respectively), lower BMI (26.58 \pm 6.30 vs. $22.49 \pm 7.71, \mathrm{p}=0.042)$, higher prevalence of malnourished patients during all follow-up (12.2 vs. $33.3 \%, \mathrm{p}=0.01$ during hospital stay; $18.3 \times 47.6 \%, \mathrm{p}=0.001$ and $7 \mathrm{x}$ $40 \%, \mathrm{p}<0.001$ after 30 and 90 days hospital discharge, respectively) and had lower handgrip strengths at moment hospital discharge and 30 days after $(16.47 \pm 8.33$ vs. $10.00 \pm 4.51, \mathrm{p}=0.04$ and $21.55 \pm 9.48$ vs. $12.00 \pm 4.97, \mathrm{p}=0.02$, respectively).

Table 5 describes the laboratory data of long-term AKI survivors and non-survivors. The two groups were similar in creatinine, BUN, albumin, haemoglobin and cholesterol levels. The non-survivors patients had higher CRP and cholesterol at 30 days after hospital discharge $(7.70 \pm 2.61$ vs. $4.17 \pm 1.07 \mathrm{mg} / \mathrm{dL}, \mathrm{p}=0.04$ and $176.30 \pm$ 64.65 vs. $210.43 \pm 59.20 \mathrm{mg} / \mathrm{dL}, \mathrm{p}=0.038$, respectively).

Twelve factors met criteria for inclusion in the multivariable analysis and long-term mortality was significantly associated with higher number of co morbidities ( $\mathrm{HR}=1.79,95 \% \mathrm{CI}=1.45-2.46$, $\mathrm{p}=0.04)$, non-recovery of kidney function at hospital discharge $(\mathrm{HR}=1.46,95 \% \mathrm{CI}=1.02-2.16, \mathrm{p}=0.03), \mathrm{BMI}<24 \mathrm{~kg} / \mathrm{m}^{2} 30$ days 
Citation: Xavier PS, Goes CR, Buffarah MB, Soncini AC, Balbi AL, et al. Handgrip Strength and Weight Predict Long-Term Mortality in Acute Kidney Injury Patients. J Urol Nephrol. 2016;3(1): 8.

ISSN: $2380-0585$

Table 4: Nutritional parameters evolution in AKI patients according to time.

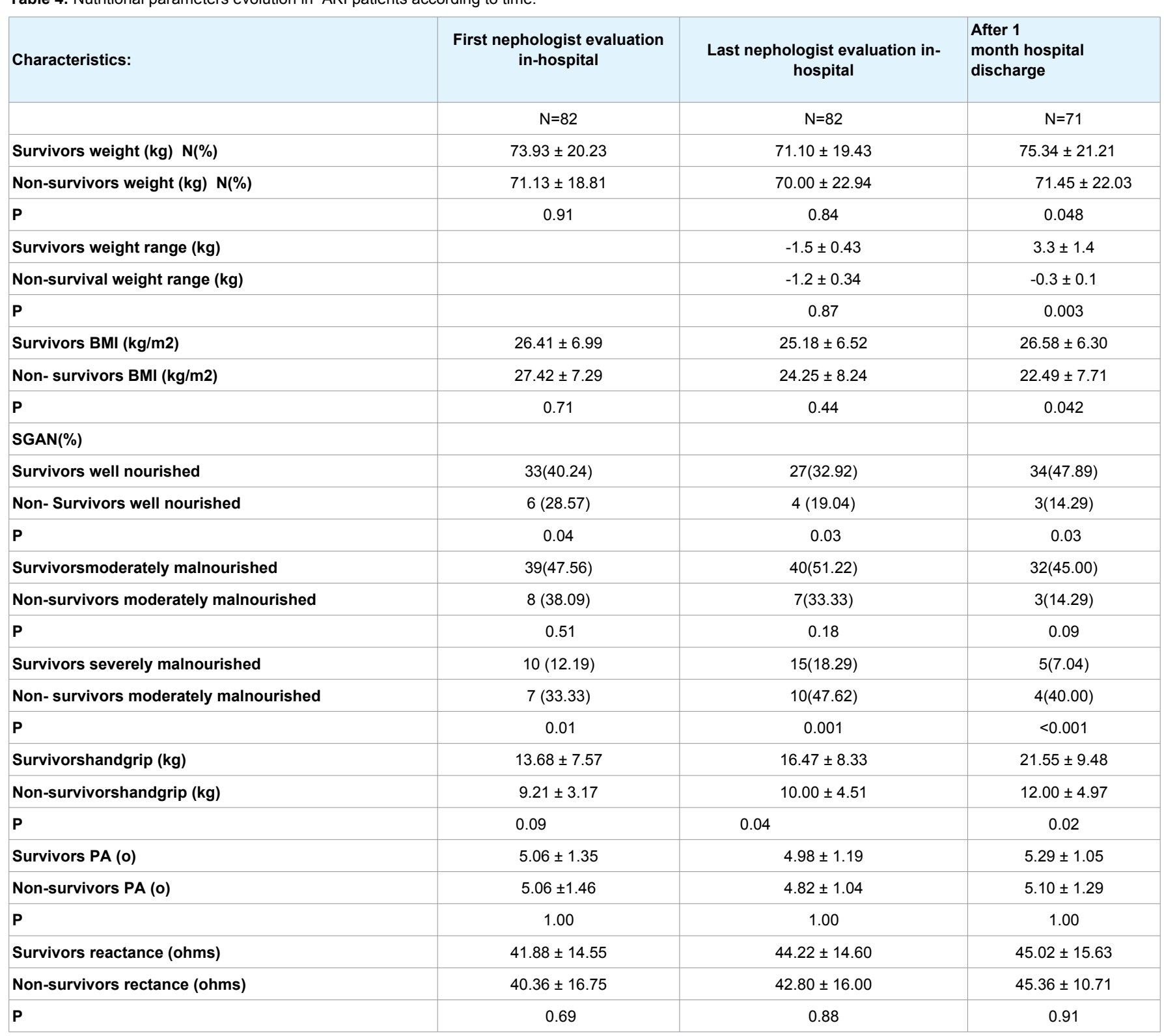

SGA: Subjective Global Assessment; FA: Phase Angle.

after hospital discharge $(\mathrm{HR}=1.95,95 \% \mathrm{CI}=1.29-3.3, \mathrm{p}=0.02)$, gain weight lower than $1 \mathrm{~kg}$ between first evaluation in-hospital stay and 30 days after hospital discharge $(\mathrm{HR}=1.95,95 \% \mathrm{CI}=1.29-3.3$, $\mathrm{p}=0.02)$, malnourished patients at hospital stay evaluation $(\mathrm{HR}=1.58$, 95\% $\mathrm{CI}=1.14-2.94, \mathrm{p}=0.01)$ and handgrip strengths lower than 10 $\mathrm{kg}$ at hospital discharge $(\mathrm{HR}=1.81,95 \% \mathrm{CI}=1.17-2.31, \mathrm{p}=0.04)$ and lower than $15 \mathrm{~kg} 30$ days after hospital discharge (HR=1.76, 95\% $\mathrm{CI}=1.21-2.44, \mathrm{p}=0.03$ ), according to Table 6 . Handgrip strength and anthropometric measurements were tested as independent variables and adjusted by age, gender, comorbidities and creatinine and severity of AKI. Interestingly, each $1 \mathrm{~kg}$ decrease in handgrip strength increased the risk of long-term mortality by $14 \%$ at the two time points.

\section{Discussion}

The studied AKI population showed similar characteristics to those described previously in literature such as older age, male sex, and presence of co morbidities, mainly hypertension, diabetes, liver disease, cancer and CKD [1-4]

The most of the patients were obese according to BMI. However, the presence of edema, very common in these patients, may have overestimated the weight and influenced this result. There was a predominance of patients with moderate malnutrition according to the classification by SGA. According to BIA, the phase angle was around 5 and the reactance of $40 \mathrm{ohms}$. The only nutritional parameter that showed statistically significant difference during in-hospital follow-up was the handgrip strength evaluated by the dynamometer.

Similar results were observed by Berbel et al. [8]. The authors assessed 113 AKI patients with clinical diagnosis of acute tubular 
Citation: Xavier PS, Goes CR, Buffarah MB, Soncini AC, Balbi AL, et al. Handgrip Strength and Weight Predict Long-Term Mortality in Acute Kidney Injury Patients. J Urol Nephrol. 2016;3(1): 8.

ISSN: $2380-0585$

Table 5: Nutritional parameters evolution in AKI patients according to long-term survival.

\begin{tabular}{|c|c|c|c|}
\hline Characteristics: & $\begin{array}{c}\text { First nephologist evaluation in- } \\
\text { hospital }\end{array}$ & $\begin{array}{l}\text { Last nephologist } \\
\text { evaluation in-hospital }\end{array}$ & $\begin{array}{l}\text { After } 1 \\
\text { month hospital diacharge }\end{array}$ \\
\hline & $\mathrm{N}=82$ & $\mathrm{~N}=82$ & $\mathrm{~N}=71$ \\
\hline Survivors creatinine(mg/dL) & $3.87 \pm 1.89$ & $2.03 \pm 0.91$ & $2.20 \pm 1.04$ \\
\hline Non-survivors creatinine (mg/dL) & $3.59 \pm 1.42$ & $2.13 \pm 1.19$ & $1.85 \pm 2.26$ \\
\hline p & 0.91 & 0.91 & 0.41 \\
\hline Survivors BUN (g/dL) & $79.41 \pm 39.52$ & $45.26 \pm 29.32$ & $35.24 \pm 26.80$ \\
\hline Non-survivors BUN (g/dL) & $64.57 \pm 66.92$ & $35.54 \pm 15.52$ & $30.91 \pm 19.32$ \\
\hline p & 0.84 & 0.24 & 0.29 \\
\hline Survivors Albumin (g/dL) & $2.99 \pm 0.79$ & $3.03 \pm 0.71$ & $3.51 \pm 0.74$ \\
\hline Non-survivors albumin (g/dL) & $2.88 \pm 0.86$ & $2.81 \pm 0.77$ & $3.63 \pm 0.85$ \\
\hline p & 0.91 & 0.24 & 0.48 \\
\hline Survivors CRP (mg/L) & $16.46 \pm 5.55$ & $9.03 \pm 4.28$ & $7.70 \pm 2.61$ \\
\hline Non-survivors CRP (mg/L) & $14.18 \pm 6.65$ & $10.34 \pm 3.64$ & $4.17 \pm 1.07$ \\
\hline p & 0.09 & 0.13 & 0.04 \\
\hline Survivors hemoglobin(g/dL) & $10.71 \pm 2.01$ & $10.61 \pm 1.88$ & $11.09 \pm 2.09$ \\
\hline Non-survivors hemoglobin (g/dL) & $9.67 \pm 1.66$ & $9.49 \pm 1.60$ & $10.36 \pm 1.84$ \\
\hline p & 0.49 & 0.51 & 0.74 \\
\hline Survivors total cholesterol (mg/dL) & $137.35 \pm 43.19$ & $143.16 \pm 46.15$ & $176.30 \pm 64.65$ \\
\hline Non-survivors total cholesterol (mg/dL) & $161.33 \pm 60.75$ & $164 \pm 59.73$ & $210.43 \pm 59.20$ \\
\hline p & 0.11 & 0.14 & 0.038 \\
\hline
\end{tabular}

CRP: C-Reactive Protein; BUN: Blood Urea Nitrogen

necrosis followed by at least seven days during hospitalization and observed that the majority of patients were overweight, phase angle was around 5 and the reactance at the end of follow-up was 40.1 ohms. Fiaccadori et al. cols applied SGA in 309 AKI patients and also found that most the patients (58\%) were malnourished [6].

Study performed by Guerra et al. evaluated 712 hospitalized patients and showed higher handgrip strength values at the time of hospital admission than those presented in this study $(19.2 \mathrm{~kg}$ in women and $37.9 \mathrm{~kg}$ in men) [16]. However, there were fewer malnourished patients (32\%) according to SGA. Norman et al. assessed 287 hospitalized patients and found lower values (26\%) of handgrip strength in malnourished patients compared to those wellnourished, according to SGA (30.82 (11-48) kg vs. 45.22 (13.51-67.7) in men and 18.5 (5.90-48.8) kg vs. $23.81(5.60-56.5) \mathrm{kg}$ in women $(\mathrm{p}<0.05)$, which may partially explain low handgrip strength values found in this study [17].

Previous studies have shown that nutritional parameters as weight, BMI and thickness of the adductor significantly influence the handgrip [17-22]. Norman et al. reported that in acute or chronic disease parameters such as disease severity, co morbidities, medical treatment and immobilization contribute to muscle weakness, decreasing the welfare of patients and changing the handgrip strength [22]. In addition to these factors, inflammation, infection, the use of steroids and muscle relaxants, hypoxia, electrolyte imbalance and oxidative stress, also have adverse effects on muscle function, compromising the hand grip [20-22].

In the present study there was a reduction in inflammation assessed by CRP $(16.2 \pm 6.0$ vs. $9.2 \pm 5.2, \mathrm{p}=0.03)$ at final follow up in hospital stay, factor that may have improved handgrip strength.

The in-hospital mortality was $13.7 \%$, which is lower than the mortality observed in other studies. This difference in mortality can be attributed to the fact that in this study the majority of patients were from wards. Many ICU patients were excluded from this study because they do not have ability to perform the handgrip strength.

There was significantly improvement in the long-term nutritional parameters. There was significant increase in albumin levels after 1 month, weight and BMI increased after 3 months, and after six months there was improvement of nutritional status according to SGA, phase angle, reactance and handgrip strength. However, by the end of follow-up $50 \%$ of patients had not yet recovered the weight they had before admission.

So far there are few studies in the literature accompanying the nutritional evolution of critically ill patients after hospital discharge and none performed in the AKI population. Lim and cols followed 163 hospitalized patients and five months after hospital discharge and observed that at the last consult there was significant increase in weight ( $44 \pm 8,5 \mathrm{~kg} \times 46.3 \pm 9,6 \mathrm{~kg}$ ), improvement in quality of life assessed by the EQ-5D VAS $(61.2 \pm 19.8 \times 71.6 \pm 17.4)$, in the handgrip strength $(15.1 \pm 7.1 \times 17.5 \pm 8.5)$ and in nutritional status in $74 \%$ of patients by ASG [23]. Study by Kvale et al. evaluated 346 critical 
Citation: Xavier PS, Goes CR, Buffarah MB, Soncini AC, Balbi AL, et al. Handgrip Strength and Weight Predict Long-Term Mortality in Acute Kidney Injury Patients. J Urol Nephrol. 2016;3(1): 8.

ISSN: $2380-0585$

Table 6: Multivariable analysis of clinical, laboratory and nutritional parameters associated with late mortality in AKI patients.

\begin{tabular}{|c|c|c|c|}
\hline Parameters & HR & $\mathrm{Cl} 95 \%$ & $\mathbf{p}$ \\
\hline$>2$ comorbidities & 1.79 & $1.45-2.46$ & 0.04 \\
\hline cancer & 1.19 & $0.98-2.16$ & 0.01 \\
\hline ICU admission & 1.14 & $0.93-1.17$ & 0.31 \\
\hline sepsis & 1.47 & $0.88-2.38$ & 0.03 \\
\hline Non-recovery of kidney function & 1.46 & $1.02-2.16$ & 0.03 \\
\hline BMI $<24 \mathrm{~kg} / \mathrm{m}^{2}$ after hospitalar discharge & 1.95 & $1.29-3.3$ & 0.02 \\
\hline $\begin{array}{l}\text { Severely malnutrished patients according SGA at first } \\
\text { nephrologist evaluation in-hospital }\end{array}$ & 1.58 & 1.14-2.94 & 0.01 \\
\hline Weight range $(\mathrm{kg})(<1 \mathrm{~kg})$ & 1.95 & $1.29-3.3$ & 0.02 \\
\hline $\begin{array}{l}\text { Hand grip at the last nephrologist evaluation in-hospital (< } \\
10 \mathrm{~kg})\end{array}$ & 1.81 & $1.17-2.31$ & 0.04 \\
\hline Hand grip at 1 month after hospital discharge $(<15 \mathrm{~kg})$ & 1.76 & $1.21-2.44$ & 0.03 \\
\hline $\begin{array}{l}\text { Total cholesterol at } 1 \text { month after hospital discharge (> } 200 \mathrm{mg} / \\
\text { dl) }\end{array}$ & 1.11 & $0.84-1.91$ & 0.52 \\
\hline
\end{tabular}

ICU: Intensive Care Unit; SGA: Subjective Global Assessment; BMI: Body Mass Index; CRP: C-Reactive Protein

patients seven months after discharge from the ICU and showed that $32 \%$ of patients reported to have lost $0-5 \mathrm{~kg}, 28 \%$ lost between 5 and $10 \mathrm{~kg}, 19 \%$ lost of $10-15 \mathrm{~kg}$ and $21 \%$ had a maximum weight loss of more than $15 \mathrm{~kg}$ during hospitalization [11]. The body weight at the follow-up consultation compared with that before the ICU stay was higher in $15 \%$ of patients, unchanged in $35 \%$ and lower in $50 \%$ of patients, which shows a persistent worsening of the nutritional status even after several months of hospital discharge and it may contribute to the poor prognosis of patients.

Mortality after 6 months of clinical follow up was 25.6\%. Multivariate analysis identified as factors independently associated with late mortality: the number of co morbidities, the presence of cancer and sepsis, lack of recovery of renal function, malnutrition at baseline, gain weight lower than $1 \mathrm{~kg}$ between first evaluation in hospital stay and 30 days after hospital discharge, and handgrip strengths lower than $10 \mathrm{~kg}$ at nephrologist discharge and lower than $15 \mathrm{~kg} 30$ days after hospital discharge.

Recently several studies have addressed the long-term outcome of patients surviving after an AKI episode and late mortality is between $15-71 \%$, depending on the population studied and the time of followup $[5,6]$. However, none of these studies evaluated the impact of nutritional factors in the late prognosis.

Data similar to those reported in our study were observed by Schiffl \& Fischer that evaluated a cohort of 425 AKI patients who needed for dialysis, of which 226 survived and were followed for 5 years after hospital discharge [2]. The predictors of mortality late were surgical admissions, co morbidities and partial recovery of renal function at the time of hospital discharge. In another study by Schiffl et al. with the same cohort of survivors followed up for 10 years after hospital discharge, late mortality rate was $80 \%$ and the recovery of renal function at the time of hospital discharge was associated with lower mortality [24]. In the same study, age, gender, co morbidities, the APACHE II score and the type of renal replacement therapy were also associated with long-term mortality.

Liano et al. studied 177 patients with previous normal renal function and surviving the AKI episode and found survival of $60 \%$ at 10 years in patients who had total recovered renal function at the time of hospital discharge, while those who had partial recovery showed lower survival (42\%). In this same study, the presence of co morbidities such as heart and liver failure, cancer, hypertension and diabetes were identified as factor independently associated with late mortality [3]. Bagshaw et al. Followed 240 surviving AKI patients for 1 year and found that the number of co morbidities, the presence of liver disease, higher APACHE II, septic shock and need for RRT were factors associated with late death [25].

In our study, no weight gain after hospital discharge and the presence of malnutrition by SGA at baseline were factors associated with late mortality. Oliveira et al. evaluated 605 hospitalized patients and found that malnutrition according to SGA, risk of malnutrition assessed by geriatric nutritional risk index (GNRI), lower BMI, albumin and pre albumin were associated with increased risk of inhospital mortality [26].

In our study, handgrip strength lower than $10 \mathrm{~kg}$ at the time of discharge from the nephrologist and lower than $15 \mathrm{~kg}$ one month after hospital discharge were associated with late mortality. Similar results were observed by Vecchiarino et al. in study that evaluated 213 hospitalized patients with pneumonia at admission and 30 days after hospital discharge [10]. The authors showed that malnutrition, inability to walk 50 meters without help and handgrip strength lower than $10 \mathrm{~kg}$ were associated with longer hospital stay, hospital readmission and death.

The handgrip strength measured by the dynamometer is an indicator of strength and muscle mass and can identify the effects of malnutrition even before the changes in body composition parameters are identified. Thus, it is a promising measure as an indicator of malnutrition in hospitalized patients. In addition, their low values are associated with outcomes such as increased postoperative complications, decreased survival in the short and long term, longer hospital stays and higher rates of hospitalization [27]. Although handgrip strength is a readily available, low-cost method, 
Citation: Xavier PS, Goes CR, Buffarah MB, Soncini AC, Balbi AL, et al. Handgrip Strength and Weight Predict Long-Term Mortality in Acute Kidney Injury Patients. J Urol Nephrol. 2016;3(1): 8.

ISSN: 2380-0585

it has some limitations. One important limitation is that a subject's cooperation is always required. In addition, there is still no absolute consensus on the measurement protocols for handgrip strength. For example, an optimal body posture or the position of the shoulder, elbow, and wrist can easily alter maximum grip strength [28]. In addition, the handheld dynamometer must be well calibrated and adjusted for hand size for accurate measurements [29].

There was no association between cholesterol and in-hospital and long-term mortality ( $\mathrm{p}=0.18$ and 0.52 , respectively). However, low cholesterol levels have been described as predictors of complications and mortality, including the AKI population. Obialo et al. identified reduction of around $50 \%$ in the survival of AKI patients who had cholesterol lower than $150 \mathrm{mg} / \mathrm{dL}$ at admission [7]. More recently, Guimarães et al. studied 56 AKI patients in ICU and showed that cholesterol levels below $96 \mathrm{mg} / \mathrm{dL}$ were associated with mortality [9].

Finally, this study has some limitations. It was conducted in a single center, follow-up was only 6 months and more severe patients were excluded.

However, despite its limitations, this is the first study that evaluated the long-term nutritional outcome of patients after an episode of AKI and identified nutritional factors associated with late mortality.

\section{Conclusion}

Interesting and useful results as non-recovery of weight, malnutrition assessed by SGA at baseline and lower handgrip strength values at discharge from hospital and 30 days after were associated with long-term mortality. Simple and ease methods can be applied in AKI patients during and after hospitalization to diagnose nutritionally patients who are at higher risk for poor prognosis and, consequently intervention measures can be performed to improve survival in long-term.

\section{References}

1. Schiffl H, Fischer R (2008) Five-year outcomes of severe acute kidney injury requiring renal replacement therapy. Nephrol Dial Transplant 23: 2235-2241.

2. Ponte B, Felipe C, Muriel A, Tenorio MT, Liaño F (2008) Long-term functional evolution after an acute kidney injury: a 10-year study. Nephrol Dial Transplant 23: 3859-3866.

3. Liãno F, Felipe C, Tenorio MT, Rivera M, Abraira V, et al. (2007) Long term outcome of acute tubular necrosis: a contribution to its natural history. Kidney Int 71: 679-686.

4. Lafrance JP, Miller DR (2010) Acute kidney injury associates with increased long-term mortality. J Am Soc Nephrol 21: 345-352.

5. James MT, Ghali WA, Tonelli M, Faris P, Knudtson ML, et al. (2010) Acute kidney injury following coronary angiography is associated with a long-term decline in kidney function. Kidney Int 78: 803-809.

6. Fiaccadori E, Lombardi M, Leonardi S, Rotelli CF, Tortorella G, et al. (1999) Prevalence and clinical outcome associated with preexisting malnutrition in acute renal failure: a prospective cohort study. J Am Soc Nephrol 10: 581 593.

7. Obialo Cl, Okonofua EC, Nzerue MC, Tayade AS, Riley LJ (1999) Role of hypoalbuminemia and hypocholesterolemia as copredictors of mortality in acute renal failure. Kidney Int 56:1058-1063

8. Berbel MN, Góes CR, Balbi AL, Ponce D (2014) Nutriotional parameters are associated with mortality in acute kidney injury. Clinics (São Paulo) 69: 476 482
9. Guimarães SM, Lima EQ, Cipullo JP, Lobo SM, Burdmann EA (2008) Low insulin growth factor-1 and hypocholesterolemia as mortality predictors in acute kidney injury in the intensive care unit. Crit Care Med 36: 3165-3170.

10. Vecchiriano P, Bohannon RW, Ferrulo J, Maljanian R (2004) Short-term outcomes and their predictors for patients hospitalized with communityacquired pneumonia. Heart Lung 33: 301-307.

11. Kvåle R, Ulvik A, Flaatten H (2003) Follow-up after intensive care: a single center study. Intensive Care Med 29: 2149-2156.

12. Kidney Disease Improving Global Outcomes (2012) KDIGO clinica precticeguidline for acute kidney. Kidney Int Suppl 2: 1-138.

13. Fisher LD, van Belle G (1993) Biostatistics: a methodology for health science. John Wiley, New York, USA

14. Incel NA, Ceceli E, Durukan PB, Erdem HR, Yorgancioglu ZR (2002) Grip strength: effect of hand dominance. Singapore Med J 43: 234-237.

15. Dourado VZ, Antunes LC, Tanni SE, Paiva SA, Padovani CR, et al. (2006) Relationship of upper-limb and thoracic muscle strength to 6 -min walk distance in COPD patients. Chest 129: 551-557.

16. Guerra RS, Fonseca I, Pichel F, Restivo MT, Amaral TF (2014) Handgrip strength cutoff values for undernutrition screening at hospital admission. Eur J Clin Nutr 68: 1315-1321.

17. Norman K, Stobaus N, Gonzalez MC, Schulzke JD, Pirlich M (2011) Hand grip strength: outcome predictor and marker of nutritional status. Clin Nutr 30: 135-142.

18. Innes E (1999) Handgrip strength testing: a review of literature. Aust OccupTher J 46: 120-140

19. Johansson CA, Kent BE, Shepard KF (1983) Relationship between verbal command volume and magnitude of muscle contraction. Phys Ther 63: 12601265.

20. Härkönen R, Piirtomaa M, Alaranta H (1993) Grip strength and hand position of the dynamometer in 204 Finnish adults. J Hand Surg Br 18: 129-132.

21. Luna-Heredia E, Martín-Peña G, Ruiz-Galiana J (2005) Handgrip dynamometry in healthy adults. Clin Nutr 24: 250-258.

22. Norman K, Stobaus N, Reiß J, Schulzke J, Valentini L, et al. (2012) Effect of sexual dimorphism on muscle strenght in cachexia. J Cachexia Sarcopenia Muscle 3: 111-116

23. Lim SL, Lin X, Chan YH, Ferguson M, Daniels L (2013) A pre-post evalution of an ambulatory nutrition support service for malnourished patients post hospital discharge: a pilot study. Ann Acad Med Singapore 42: 507-513.

24. Schiffl H, Lang SM, Fischer R (2012) Long-term outcomes of survivors of ICU acute kidney injury requiring renal replacement therapy: a 10-year prospective cohort study. Clin Kidney J 5: 297-302.

25. Bagshaw SM, Laupland KB, Doig CJ, Mortis G, Fick GH, et al. (2005) Prognosis for long-term survival and renal recovery in critically ill patients with severe acute renal failure: a population-based study. Crit Care 9: R700-R709.

26. Study Group of Hyperglycemia in Parenteral Nutrition; Nutrition Area of the Spanish Society of Endocrinology and Nutrition (SEEN) (2013) The subjective global assessment predicts in-hospital mortality better than other nutrition-related risk indexes in noncritically ill inpatients Who receive parenteral nutrition in Spain (prospective multicenter study). J Acad Nutr Diet 113: $1209-1218$.

27. Gumieiro DN, Rafacho BP, Gradella LM, Azevedo PS, Gaspardo D, et al. (2012) Handgrip strength predicts pressure ulcers in patients with hip fractures. Nutrition 28: 874-878.

28. Luna-Heredia E, Martín-Peña G, Ruiz-Galiana J (2005) Handgrip dynamometry in healthy adults. Clin Nutr 24: 250-258.

29. Bauer JM, Sieber CC (2008) Sarcopenia and frailty: a clinician's controversial point of view. Exp Gerontol 43: 674-678. 